\title{
Integrated Design Method Research on Performance and Reliability of Ship Steam Turbine
}

\author{
Xiaojie Zhang ${ }^{1, *}$, Sheng Hong ${ }^{2, *}$, Longlong Sun $^{2}$, HaoYuan ${ }^{3}$ and Xiaorui Zhang ${ }^{4}$ \\ ${ }^{1}$ The 714 Research Institute, CSIC, No. 55, Kehui Road, Chaoyang District, Beijing 100012, China \\ ${ }^{2}$ School of Reliability and System Engineering, Beihang University, No. 37, Xue Yuan Road, Beijing 100191, China \\ ${ }^{3}$ Planning \& Developing Strategy Reserch Centre, CSIC, No. 5, Yuetan North Street, Xicheng District, Beijing 100861, China \\ ${ }^{4}$ Mapping Office of Yangquan, Yangquan Urban Planning Bureau, Nanda Street, Cheng District, Yangquan 045000, China \\ ${ }^{*}$ Corresponding author
}

\begin{abstract}
For the integrating combination problems of performance and reliability on ship products, the collaborative design architecture of multi-characteristics of ship mechanical and electrical products is researched. And on the case of integration design of ship steam turbine performance and reliability, the thermodynamics and strength properties are designed using boundary method and finite element analysis. And then steam turbine weakness is analyzed based on the discussion of failure mechanism and failure regularity. Finally, the integrating design method of performance and reliability of ship steam turbine is designed. The result states that multicharacteristics engineering problems are solved, the design level is effectively improved, and the design is a reference for the integration design of performance and reliability of other weapon.
\end{abstract}

Keywords-steam turbine; thermodynamic; strength; performance; reliability;integrating design

\section{INTRODUCTION}

Multi-fault and short-life products often appear because of the serious gap of performance and reliability design, resulting in the low-level reliability products in the ship mechanical and electrical products design process ${ }^{[1 \sim 15]}$. There are two types of ship mechanical and electrical products problems: one is performance problem. The units can't reach the requirements on normally working. The other is reliability problem. The products can't reach requirements because of uncoordinated design and mismatch parameters. The main reasons causing ship mechanical and electrical quality problems are lack of methods and means of integrating design of performance and reliability, and the collaborative design is not reached ${ }^{[1,2,5,9]}$. Therefore, it is not only the problem, but also the urgent needs that how to reach the synchronous design and analysis of ship mechanical and electrical products, in order to integrate the reliability and performance design ${ }^{[3 \sim 11]}$. The domestic research on the integration design started late. Only small-range and single-area researches are done on some special weapons, such as plane and missile in a few of research institutes and researchers, and the research results were not applied to the engineering design ${ }^{[12 \sim 16]}$. So, the integration design of performance and reliability is needed to be researched in order to improve the development requirements of ship mechanical and electrical products and ensure the performance and reliability design simultaneously ${ }^{[17 \sim 20]}$.

\section{ARCHITECTURE/ IDEA OF INTEGRATION DESIGN METHOD OF SHIP PRODUCTS MULTI-QUALITY CHARACTERISTICS}

The integration design of performance and reliability of ship mechanical and electrical products is to combine the performance analysis and reliability analysis, and balance the performance analysis and reliability design in the ship typical product design, in order to achieve collaborative combination, release the mismatch phenomenon in such as design method, product technical state, and working process etc. Therefore, shortening development cycle, decreasing lifecycle cost, and reducing risk are reached to solve engineering problems in the performance and reliability design ${ }^{[17 \sim 20]}$, and enhance the base to optimize the subsequent performance and reliability integration design. Its technical ideas shown in Figure I

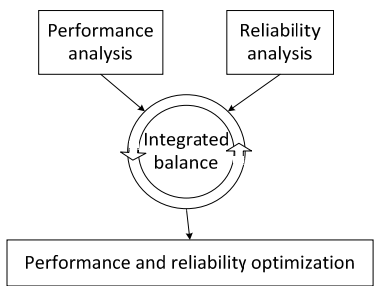

FIGURE I. INTEGRATION DESIGN METHOD OF SHIP PRODUCTS MULTI-QUALITY CHARACTERISTICS

The engineering case in the ship performance and reliability integration design is given in the paper with ship steam turbine as a typical mechanical and electrical product. Strength performance design parameters are calculated based on finite element method ${ }^{[9,11,14,15]}$. The Natural frequency and each order vibration frequency of according performance unit are calculated based on the Energy method and pilkey model. All the data are from thermodynamics calculation in the circulation sections [18 20]. The according performance units' reliability is calculated using the stress-strength model based on the according stress and vibration frequency. Combining the structure and relationship of the according performance units, the system engineering model of ship steam turbine is derivate, the reliability system reliability model is set up, and the steam turbine reliability is calculated. 
It is checked whether the calculated system reliability satisfied the requirement; if does, the integration design is complete; if not do, the key design parameters is adjusted back to the thermodynamics performance calculation process. The most important performance parameters is design as the key design parameters, which influent the thermodynamics and strength performance and determine the adjust direction and magnitude, by calculating the function units importance to the steam turbine system reliability, choosing the most important function units, and calculating performance parameters importance to the reliability influence of the above importance units. The adjusted key parameters are recalculated in the thermodynamics, strength and reliability formula, and then the results are compared with the requirements. If does, the integration design is done; if not do, iterate, until the requirement is satisfied.

\section{PREPARE Your PAPER BEFORE STYLING}

In order to reach the synchronization of reliability and performance, first the quantitative relationship is set up between performance and reliability, the variable and requirement relationship is set up using stress-strength model by discussing the relationship. And then, the optimized results satisfy both the performance and reliability requirements by mutual combination and constraint.

The performance and reliability integration design is analyzed taking single-cylinder, single-axis variable speed condensing steam turbine in certain ship for example in the article. The steam turbine units are classified to key function units and affiliated function units by the frequency and impact of failure, difficulty of design, manufacturing and cost perspectives. The performance parameters in the key function units include modulus of elasticity of the blade, shear modulus, density, value and installation height, density and operating speed of the wheel and the rotor density, elastic modulus, Poisson's ratio, bearing stiffness and span deviation change values.

\section{A. Analysis Calculation of the Ship Steam Turbine Thermodynamics Performance}

The main requirements of the steam turbine in certain ship are shown in TABLE I.

TABLE I. THE MAIN REQUIREMENTS OF THE STEAM TURBINES

\begin{tabular}{|c|c|c|}
\hline No. & requirements & parameters \\
\hline 1 & model & $\begin{array}{l}\text { Single-cylinder, single-axis variable } \\
\text { speed condensing steam turbine }\end{array}$ \\
\hline 2 & $\begin{array}{l}\text { Full-speed ahead rated } \\
\text { oparation power }\end{array}$ & $3000 \mathrm{~kW}$ \\
\hline 3 & $\begin{array}{l}\text { Full-speed ahead rated } \\
\text { oparation rotated speed }\end{array}$ & $3900 \mathrm{r} / \mathrm{min}$ \\
\hline 4 & steering & clockwise from head to tail \\
\hline 5 & main steam pressure & $0.95 \mathrm{MPa}$ \\
\hline 6 & main steam temperature & $208^{\circ} \mathrm{C}$ \\
\hline 7 & $\begin{array}{l}\text { full-speed ahead rated } \\
\text { operation intake air }\end{array}$ & $29000 \mathrm{~kg} / \mathrm{h}$ \\
\hline 8 & condenser pressure & $35.0 \mathrm{kPa}$ \\
\hline 9 & ahead level & 7th pressure level \\
\hline 10 & $\begin{array}{lr}\begin{array}{l}\text { full-speed ahead } \\
\text { operation } \\
\text { consumption }\end{array} & \begin{array}{r}\text { rated } \\
\text { steam }\end{array} \\
\end{array}$ & $9.374 \mathrm{~kg} / \mathrm{kWh}$ \\
\hline
\end{tabular}

According to the main requirements of the steam turbine in TABLE I, the basic geometric data is designed for steam turbine circulation section in TABLE II.

TABLE II. BASIC GEOMETRIC DATA OF THE STEAM TURBINE CIRCULATION

\begin{tabular}{|c|c|c|c|}
\hline order & blade root $(\mathbf{m m})$ & blade height $(\mathbf{m m})$ & blade outlet angle $\left.\mathbf{(}^{\circ}\right)$ \\
\hline $\mathbf{1}$ & 815 & 14 & 17.13 \\
\hline $\mathbf{2}$ & 815 & 19 & 16.946 \\
\hline $\mathbf{3}$ & 815 & 25 & 17.219 \\
\hline $\mathbf{4}$ & 815 & 35 & 17.248 \\
\hline $\mathbf{5}$ & 802 & 48 & 17.898 \\
\hline $\mathbf{6}$ & 781 & 69 & 18.403 \\
\hline $\mathbf{7}$ & 760 & 90 & 23.035 \\
\hline
\end{tabular}

According to the geometric data in the TABLE II, steam turbine rated conditions thermodynamic process line can be obtained as shown in Figure II and part of the thermodynamic calculation results shown in TABLE III are obtained by using the analysis software of integration design of ship steam turbine performance and reliability to calculate the thermodynamics performance in the steam turbine.

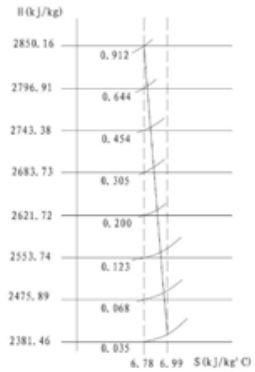

FIGURE II. STEAM TURBINE RATED CONDITION OF THERMAL PROCESS LINE

TABLE III. STEAM TURBINE RATED CONDITION OF THERMAL CALCULATION RESULTS

\begin{tabular}{|c|c|c|c|c|c|c|c|}
\hline \multirow{2}{*}{ Item } & \multicolumn{7}{|c|}{ Pressure level } \\
\cline { 2 - 8 } & 1 & 2 & 3 & 4 & 5 & 6 & 7 \\
\hline $\begin{array}{c}\text { Steam turbine } \\
\text { speed } \\
\text { (n,r/min) }\end{array}$ & \multicolumn{7}{|c|}{3900} \\
\hline $\begin{array}{c}\text { The } \\
\text { calculation of } \\
\text { flow (G,t/h) }\end{array}$ & 28.58 & 28.32 & 28.32 & 28.32 & 28.32 & 28.32 & 28.32 \\
\hline $\begin{array}{c}\text { Leaf blade } \\
\text { height (I2,mm) }\end{array}$ & 14 & 19 & 25 & 35 & 48 & 69 & 90 \\
\hline $\begin{array}{c}\text { Leaf blade } \\
\text { outlet pressure } \\
\text { (p2, Mpa) }\end{array}$ & 0.64 & 0.45 & 0.31 & 0.20 & 0.12 & 0.07 & 0.04 \\
\hline
\end{tabular}

B. Strength Performance Analysis Calculation of Each Function Unit in the Ship Steam Turbine

According to the type line of data on flow passage and aerodynamic data, calculate the feature of stress and vibration frequency distribution and calculate the specific parameters. 


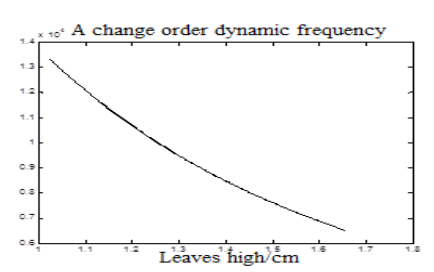

FIGURE III. 1ST ORDER MOVING FREQUENCY WITH BLADE HEIGHT VARIATION

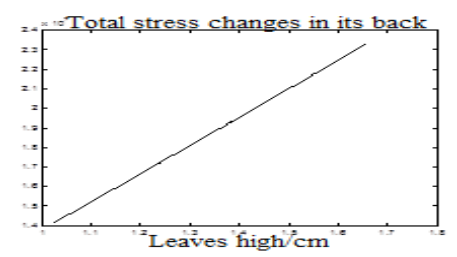

FIGURE IV. SECTION BACK TOTAL STRESS WITH THE BLADE HEIGHT VARIATION

TABLE IV. STRENGTH PERFORMANCE RESULTS OF CERTAIN BLADE

\begin{tabular}{|c|c|c|c|c|c|c|c|c|}
\hline \multirow{2}{*}{ I } & \multicolumn{4}{|c|}{$\begin{array}{c}\text { The total stress the 14 } \\
\text { section size (MPa) }\end{array}$} & \multicolumn{3}{c|}{ Dangerous frequency size (Hz) } \\
\cline { 2 - 9 } & Max & Min & Ave & Sta & Max & Min & Ave & Sta \\
\hline A & 19.6 & 19.6 & 19.6 & -4.9 & 8738 & 8029 & 8462 & 127 \\
\hline B & 21.6 & 17.1 & 19.5 & 0.99 & 9057 & 8075 & 8503 & 217 \\
\hline C & & & 19.6 & 0.24 & 8480.0 \\
\hline D & 23.3 & 14.2 & 19.2 & 0.20 & 13329 & 6528 & 8841 & 1401 \\
\hline
\end{tabular}
order; A- Modulus of elasticity; B- density; C- Install the value; D- height.

TABLE V. STRENGTH PERFORMANCE RESULTS OF ROTARY TABLE

\begin{tabular}{|c|c|c|}
\hline \multirow{2}{*}{ influences } & \multicolumn{2}{|c|}{ dangerous section total stress (MPa) } \\
\cline { 2 - 3 } & Average & Standard deviation \\
\hline density & 172.42 & 0.7581 \\
\hline $\begin{array}{c}\text { working } \\
\text { rotary speed }\end{array}$ & 170.2 & 18.19 \\
\hline
\end{tabular}

TABLE VI. STRENGTH PERFORMANCE RESULTS OF ROTOR

\begin{tabular}{|c|c|c|}
\hline \multirow{2}{*}{ influence factor } & \multicolumn{2}{|c|}{ critical speed of revolution (rpm) } \\
\cline { 2 - 3 } density & The mean & standard deviation \\
\hline Modulus of elasticity & 8113.04 & 192.72 \\
\hline Poisson's ratio & 8093.72 & 13.13 \\
\hline $\begin{array}{c}\text { The bearing stiffness } \\
\text { of deviation }\end{array}$ & 8093.30 & 3.67 \\
\hline Changes span value & 7998.45 & 25.59 \\
\hline
\end{tabular}

C. Reliability Analysis Calculation of the Ship Steam Turbine Function Units

Calculation shows the following core features (blade, roulette, rotor) reliability analysis and calculation results, MTBF the first level blade $=360000000 ;$ MTBF the second blade $=$ 360000000; $\mathrm{MTBF}_{\text {the third stage blade }}=12000000 ; \mathrm{MTBF}$ the fourth stage blade $=600000$; $\mathrm{MTBF}$ the fifth stage blade $=16000 ; \mathrm{MTBF}$ the six stage blade $=5000 ; \quad$ MTBF the seventh blade $=180000 ;$ MTBF The rotor $=360000000 ;$ MTBF roulette $=360000000$.

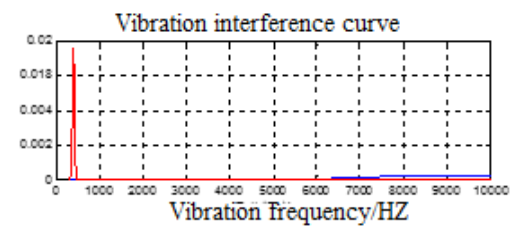

FIGURE V. VIBRATION INTERFERENCE CURVE WITH BLADE HEIGHT INFLUENCE

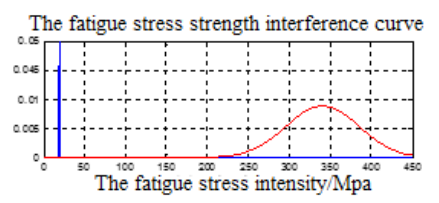

FIGURE VI. FATIGUE INTERFERENCE CURVE WITH BLADE HEIGHT INFLUENCE

The steam turbine faults caused by accessories function units are few, and the accessory works well, so the accessory function units reliability are calculated by applying the reliability-fault ratio model. Accessories function units' fault ratio and reliability are shown in TABLE VII .

TABLE VII. ANALYSIS RESULTS OF THE ASSESORIES RELIABILITY

\begin{tabular}{|l|c|c|}
\hline accessories & Failure rate (times/ millions h) & MTBF(h) \\
\hline spring & 8.17998 & 120000 \\
\hline $\begin{array}{l}\text { bolt } \\
\text { connections }\end{array}$ & 8.49 & 120000 \\
\hline The seals & 7.3392 & 120000 \\
\hline The motor & - & 360000 \\
\hline
\end{tabular}

\section{Reliability Analysis Calculation of Ship Steam Turbine} System

Series connected seven stages blades are combined to a blade system and the calculated blade system MTBF (Mean Time Between Faults) using series connection is 3700 hours in the ship steam turbine. Blades, rotary table and rotor are important units of the key function units, and they are series connected to the host rotor in the steam turbine. Springs use series-parallel connection structure; bolt use get-k-from-n structure as a clamping connection member. Motor subsystem is series connection that provides power for the auxiliary system and has no redundancy. Seals are used often in the steam turbine, including steam seal, static seal connecting the upper and lower cylinders, and gaskets connecting flanges. Here, six bolts and one gasket are chosen to calculate the steam turbine system reliability. According to the picture mapping relationship of the each function units in the steam turbine system, reliability block diagram model is established for the ship steam turbine, shown in the Figure VII.

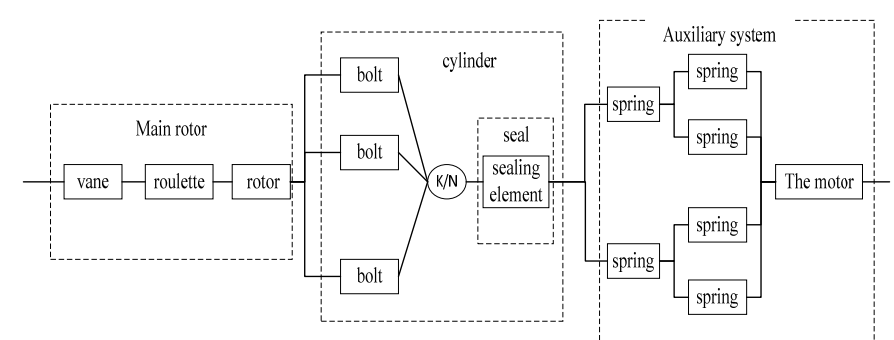

FIGURE VII. BLOCK MODEL OF THE STEAM TURBINE SYSTEM RELIABILITY 
According to the reliability block diagram, the reliability formula is obtained and then the calculated MTBF is 3500 hours by substituting the each function unit reliability into the formula.

"Five characteristics" requirements of certain ship steam turbine is 100,000 hours in the same ship, and satisfy the GJB 1371-92. The steam turbine MTBF is 4,000 hours, that is

\section{$\mathrm{TBF}=4000$ hours}

By comparison, the reliability of steam turbine does not satisfy the requirement of reliability design (MTBF steam turbine $=3500<4000=\mathrm{TBF}$ ), so the performance and reliability integration optimization design is used to the ship steam turbine/gas turbine.

\section{E. The Optimization Design for The Performance and Reliability of Ship Steam Turbine}

To determine each functional component fault of steam turbine/failure affect the importance of the gas turbine system, and according to the important degree of each functional unit. Expressed as a symbol of IP the importance degree of each function unit is IP (i) said the importance degree of the it's a parts and defined

$$
I_{P}(\mathrm{i})=\frac{\partial}{\partial R_{\mathrm{i}}} R_{S}
$$

According to the above definition can calculate steam turbine the importance degree of each feature and into the corresponding numerical, have the IP (blade) $=0.981$; IP (roulette) $=0.891 ; \mathrm{IP}$ (axis) $=0.891 ; \mathrm{IP}($ spring $)=0.893 ; \mathrm{IP}$ (bolt connectors $)=0.897 ; \mathrm{IP}($ motor $)=0.893 ; \mathrm{IP}($ seals $)=0.904$.

The most important function unit in the ship steam turbine is blade in the above article, in other words, the blade reliability is the most important one of the system reliability, so the most effective method to improve reliability is to improve the blade reliability in the ship steam turbine system.

There are seven stage blades series connected in the steam turbine blade system. The importance of every blade is obtained using function unit importance law. They are shown respectively: Ip (the first level blade) $=0.907$; Ip (the second blade $)=0.907$; Ip (the third stage blade $)=0.907$; Ip ( 4 blade $)=$ 0.907; Ip (the fifth leaf) $=0.928$; Ip (6 blade) $=0.976$; Ip (the seventh blade) $=0.909$.

The reliability of the 6th stage blade, 5th stage blade and 7th stage blade are more important ones to the blade system by the decreasing importance sequence and the reliability of the 6th stage blade is the most important one to the reliability of the blade system.

The most important parameters to the blade reliability are obtained by the key influence analysis method. The parameter importance of the 6th stage blade reliability is represented by the ratio of the 6th stage reliability and according reliability of each parameters, which is shown in the Equation (2).

$\mathrm{IP}(\mathrm{i})=\mathrm{R}$ Leaf blade reliability $/ \mathrm{Ri}$ The influence factors of reliability

According to the formula (2), can draw the importance degree of each design parameter are: $\operatorname{IP}\left(E, S_{V}\right)=0.929$;
$\operatorname{IP}\left(G, S_{V}\right)=0.929 ; \operatorname{IP}\left(p, S_{V}\right)=0.929 ; \operatorname{IP}\left(h, S_{V}\right)=1 ; \operatorname{IP}\left(E, S_{F}\right)=0.929 ;$ $\operatorname{IP}\left(\mathrm{G}, \mathrm{S}_{\mathrm{F}}\right)=0.929 ; \quad \mathrm{IP}\left(\mathrm{p}, \mathrm{S}_{\mathrm{F}}\right)=0.929 ; \quad \mathrm{IP}\left(\mathrm{b}, \mathrm{S}_{\mathrm{F}}\right)=0.929 ; \quad \mathrm{IP}(\mathrm{h}$, $\mathrm{S}_{\mathrm{F}}=0.929$ 。 Among them: the $\mathrm{S}_{\mathrm{V}}$ to vibration intensity; $\mathrm{S}_{\mathrm{F}}$ for fatigue strength.

The blade height is the most important to the 6th stage blade reliability by all the design parameters importance. The design parameters importance of the 5th stage blade is obtained by the same method. The blade height is the most important considering vibration reliability; installation is the most important considering the fatigue reliability. Therefore, blade height and installation are the key elements influencing the blade reliability. That is, the blade height and installation are adjusted first to improve the blade reliability.

Taking the 6th stage blade for example, the reliability is decreased because of the 6th stage blade height resulting the closeness of the first stage moving frequency and the operating frequency, by the vibration and strength calculation. The research on the fault mechanism and regularity of the ship steam/gas turbine derivatives the relationship between the first stage moving frequency and the blade height, shown in figure 18. Therefore, adjusting the blade height suitable can increase the first moving frequency. Because the first moving frequency is greater than the operating frequency, keeping the above frequencies away can improve the reliability of the six blade. Decreasing the blade height $2 \mathrm{~mm}$ keeps the moving frequency away from the mean operating frequency, to improve the 6th stage blade reliability.

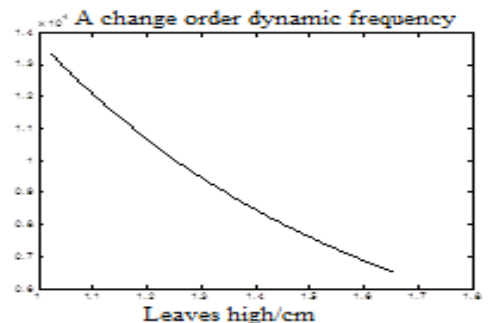

FIGURE VIII. 1ST MOVING FREQUENCY LAW WITH BLADE HEIGHT VARIATION

Installation has great influences on the fatigue. Seen by the research on the fault mechanism and regularity of the ship steam/gas turbine, the installation is optimized by the performance calculation, and can't be changed randomly, so the value is not adjusted.

- Thermodynamic Performance Calculation of Loop Iteration

The 6th stage blade height has greater influence on the steam turbine system reliability by the reliability analysis result, so the reliability is improved by adjusting the height. For satisfying the turbine circulation requirements, the quantity of the 6th stage blades is adjusted, decreasing from 144 to 142 , and the blade height is reduced from $69 \mathrm{~mm}$ to $67 \mathrm{~mm}$. The rated operating thermodynamics results of the steam turbine are shown in TABLE VIII. 
TABLE VIII. THE RATED OPERATING THERMODYNAMICS ITERATION RESULTS OF THE STEAM TURBINE

\begin{tabular}{|c|c|c|c|c|c|c|c|}
\hline \multirow{2}{*}{ Item } & \multicolumn{7}{|c|}{ Pressure level } \\
\cline { 2 - 8 } & $\mathbf{1}$ & $\mathbf{2}$ & 3 & 4 & 5 & $\mathbf{6}$ & 7 \\
\hline $\begin{array}{c}\text { Steam } \\
\text { turbine } \\
\text { speed } \\
\text { (n,r/min) }\end{array}$ & \multicolumn{7}{|c|}{3900} \\
\hline $\begin{array}{c}\text { The } \\
\text { calculation } \\
\text { of flow } \\
\text { (G,t/h) }\end{array}$ & 28.58 & 28.58 & 28.58 & 28.58 & 28.58 & 28.58 & 28.58 \\
\hline $\begin{array}{c}\text { Leaf blade } \\
\text { height } \\
\text { (12,mm) }\end{array}$ & 14 & 14 & 14 & 14 & 14 & 14 & 14 \\
\hline $\begin{array}{c}\text { Leaf blade } \\
\text { outlet } \\
\text { pressure } \\
\text { (p2, Mpa) }\end{array}$ & 0.64 & 0.64 & 0.64 & 0.64 & 0.64 & 0.64 & 0.64 \\
\hline
\end{tabular}

Comparing the two results, the relative internal efficiency of the 6th blade is reduced from 0.7518 to 0.7498 , internal power is reduced from $566.47 \mathrm{~kW}$ to $564.93 \mathrm{~kW}$, and the performance of the blade is reduced slightly. All of these also satisfy the overall performance requirements of the steam turbine.

\section{- The Strength Calculation of Loop Iteration}

Because only the blade height is optimized here and other function units are not adjusted, only the vibration fatigue strength results are shown in the following table for dangerous section of the 6th blade (14 section back).

\section{TABLE IX. STRENGTH AND VIBRATION PERFORMANCE RESULTS} OF THE 6TH BLADE

\begin{tabular}{|c|c|c|c|c|c|c|c|c|}
\hline \multirow[t]{2}{*}{ I } & \multicolumn{4}{|c|}{$\begin{array}{l}\text { The total stress the } 14 \\
\text { section size (MPa) }\end{array}$} & \multicolumn{4}{|c|}{$\begin{array}{l}\text { Dangerous frequency size } \\
(\mathrm{Hz})\end{array}$} \\
\hline & Max & Min & Ave & Sta & Max & Min & Ave & Sta \\
\hline $\mathbf{A}$ & 105 & 105 & 105 & 0.04 & 671 & 600 & 636 & 13.7 \\
\hline B & 105 & 105 & 105 & 0.08 & 639. & 636 & 638 & 0.71 \\
\hline C & 115 & 90.9 & 103. & 5.47 & 685 & & & \\
\hline D & & & 105 & 13.7 & 638 & & & \\
\hline
\end{tabular}

D- height .

- $\quad$ Ship steam turbine key features reliability calculation of loop iteration

Substituting the iteration results of blade vibration and fatigue to the stress-strength interference model, the iteration reliability results are obtained. They are, MTBF the first level blade $=360000000$; MTBF the second blade $=360000000$; MTBF the third stage blade=12000000; MTBF the fourth stage blade=720000; MTBF the fifth stage blade=16000; MTBF the six stage blade $=7500$; MTBF the seventh blade $=900000$.

- $\quad$ Ship steam turbine system reliability iterative result and analysis

The MTBF of steam turbine is 5,000 hours by substituting the blade system's MTFB of 5,300 hours and the blade reliability iteration results to the steam turbine system reliability formula. The results satisfy the reliability requirements of the steam turbine, and the performance and reliability integration design is complete for the ship steam/gas turbine.

\section{CONCLUSION}

The reliability model of steam turbine is set up by calculating the thermodynamics and strength results of ship steam turbine and combining the performance calculation and reliability analysis of each function unit. And then the steam turbine system reliability is obtained based on the calculating each unit. Therefore, the improved integrated design efficiency, the shorten development cycle, the reduced cost and the decreasing workload, are the references to the following ships' performance and reliability integration optimization design. By completing the iteration according to the system reliability requirements of the steam turbine, the disjointed problems of steam turbine performance and reliability are solved effectively to improve the steam turbine reliability design.

\section{ACKNOWLEDGMENT}

The work was partly supported by National Natural Science Foundation of China (61304111), National Program on Key Basic Research Program of China (No. 2014CB744904), and Fundamental Research Funds for the State Administration of Science Technology and Industry for National Defense PRC (No. JSJC2013207CZ04).

\section{REFERENCES}

[1] Center N S W. Handbook of reliability prediction procedures for mechanical equipment[M]. Carderock Division, Naval Surface Warfare Center, 1998

[2] Yuexiaojie,Wangshaoping,Guoxiaohe. Study on Hydraulic Component Design Based on Reliability[J]. Machinery Design \& Manufacture, 2007, (4): 11-13.

[3] Sheng Hong, Chuan Lv, Tingdi Zhao, et al. Cascading failure analysis and restoration strategy in an interdependent network [J]. Journal of Physics A: Mathematical and Theoretical, 2016, 49(19): 195101.

[4] Sheng Hong, Xiaojie Zhang, Juxing Zhu, et al. Suppressing failure cascades in interconnected networks: Considering capacity allocation pattern and load redistribution[J]. Modern Physics Letters B, 2016, 30(05): 1650049.

[5] Xiaqing,Qianshan,Zhangshifeng,Caihong. Primary Study of Reliability and Performance Incorporate Design of Aerocraft[J]. Journal of Projectiles,Rockets,Missiles and Guidance, 2009, 29(1): 257-259.

[6] Sheng Hong, Baoqing Wang, Xiaomin Ma, et al. Failure cascade in interdependent network with traffic loads[J]. Journal of Physics A: Mathematical and Theoretical, 2015, 48(48): 485101.

[7] Sheng Hong, Hongqi Yang, Tingdi Zhao, et al. Epidemic spreading model of complex dynamical network [J]. International Journal of Systems Science, 2015, 1-8.

[8] Sheng Hong, Hongqi Yang, Zio E, et al. A novel dynamics model of fault propagation and equilibrium analysis in complex dynamical communication network [J]. Applied Mathematics and Computation, 2014, 247: 1021-1029.

[9] Yuhongyan, Liuqiongjun, Chenjianjiang. Integrated Optimization on Vehicle Performance Design and Reliability Design[C]

[10] Sheng Hong, Hongqi Yang, et al. Analysis of propagation dynamics in complex dynamical network based on disturbance propagation model [J]. International Journal of Modern Physics B 28.22 (2014)

[11] Nagpal V K, Rubinstein R, Chamis C C. Probabilistic structural analysis to quantify uncertainties associated with turbopump blades[J]. AIAA journal, 1989, 27(6): 809-813. 
[12] Sheng Hong, Zheng Zhou, Enrico Zio, et al. Condition assessment for the performance degradation of bearing based on a combinatorial feature extraction method [J], Digital Signal Processing, 2014, http://dx.doi.org /10.1016/j.dsp.2013.12.010.

[13] Sheng Hong, Zheng Zhou, Zio E, et al. An adaptive method for health trend prediction of rotating bearings [J]. Digital Signal Processing, 2014, 35: $117-123$

[14] Chenzhicheng, Yaolu, Yangjianjun. ON INTEG R ATIVE SIMULATION OF PER FOR MANCE AND R ELIABILITY FO R CONVENTIONAL SUBMA $\mathrm{R}$ INE CHA R GING MISSION[J].Computer Applications and Software, 2013, 30(9): 231233.

[15] Sheng Hong, Baoqing Wang, Li G, et al. Performance Degradation Assessment for Bearing Based on Ensemble Empirical Mode Decomposition and Gaussian Mixture Model [J]. Journal of Vibration and Acoustics, 2014, 136(6): 061006.

[16] Wangzhangqi,Duanwei,Xufei,Pengzhenzhong. Strength Analysis of Steam Turbine Blade on theStochastic Finite Element Method[J]. Proceedings of the CSEE, 2006, 26(23): 88-94.

[17] Steele J. M., Lam T. C. T.. Stress and Fatigue Analysis of Steam Turbine Blades with ANSYS[C]//ANSYS Conference. 1993.

[18] Yangjiming,Yanxiaozhong, Chenyulin,Yuanrui. Strength Calculation and Analysis of Rupture Blade Accidents of Steam Turbine[J].Journal of Changsha University of Electric power(NATURAL SCIENCE), 2003, 18(2): 71-74.

[19] Shijingyuan, Huxianyue. Some New Developments in the Research of Steam Turbine Strength[J]. ShangHai QiLunJi, 2002, (1): 1-6.

[20] Sheng Hong, Zheng Zhou, Chen Lu, Baoqing Wang, Tingdi Zhao. Bearing remaining life prediction using Gaussian Process Regression with composite kernel functions [J]. Journal of Vibroengineering. 2015. 